\title{
Penggunaan New Media dalam Promosi Pariwisata Daerah Situs Cagar Budaya di Indonesia
}

\author{
Ida Ri'aeni \\ Universitas Muhammadiyah Cirebon
}

\begin{abstract}
Using new media, the limitations of space and time will no longer be an obstacle in introducing tourism place and attracting tourists to visit. The use of new media can also make regional tourism in Indonesia grew more rapidly. The tourism sector is one of the expected development of the sector can be a major source of foreign exchange, expand, and create the enterpreneur opportunity as well as employment. Almost all countries in the world are trying to develop the tourism industry. The tourism industry has a bright prospect and is considered quite promising and brings many profits. The country has been managing the tourism sectors intensively and professionally to be foreign exchange revenue of the industry that accounts for a large number of countries.

This research uses descriptive qualitative approach. The use of new media such as twitter, facebook, and internet sites can be utilized by Governments and private parties to be able to introduce objects and attractions that exist in the area. The focus in the research is: (1) what are the new media of promotion of cultural heritage in tourism areas in Cirebon? (2) How is the effectiveness of the use of new media in such promotional activities?

In Cirebon, the development of the tourism potential of the region is able to give a positive impact with the piesence of a great change in the life of the community. Economically, tourism is impacted in the expansion of the field of business and job opportunities, increase annual income and devisa in foreign countries. In the field of social life, social interaction occurs between the cultures of immigrants and the local population. It cause a change in the way of life of society as well as the occurrence of social integration. Next in anthropological concepts, knowledge of the culture and values of local wisdom are more sustainable and widely known.
\end{abstract}

Keywords: New Media, Sites Of Cultural Heritage, The Promotion Of Tourism.

\section{A. Pendahuluan}

Penelitian ini mengeksplorasi penggunaan new media dalam promosi pariwisata khususnya dalam wisata sejarah tentang situs cagar budaya yang menjadi kekayaan Indonesia. Penggunaan perkembangan ilmu pengetahuan dan perkembangan masyarakat yang mampu membawa masyarakat pada sebuah kemajuan dalam tingkatan sesama manusia.
Indonesia mempunyai potensi besar untuk menjadi kawasan tujuan wisata dunia, karena mempunyai tiga unsur pokok yang membedakan Indonesia dengan negara lain. Hal itu merupakan daya tarik wisatawan untuk mengunjungi Indonesia, karena rasa keingin tahuannya. Ketiga unsur tersebut adalah masyarakat (people), alam (nature heritage) dan budaya (cultural heritage). Pertama, Masyarakat Indonesia terkenal dengan

${ }^{1}$ Yoeti A. Oka, 1992. 
keramahannya dan bisa bersahabat dengan bangsa manapun. Potensi ke dua adalah alam (nature heritage). Indonesia mempunyai alam yang indah, yang tidak setiap Negara memilikinya, misalnya pegunungan yang ada di setiap pulau, pantai yang indah, goa, serta hamparan sawah yang luas dan enak untuk dinikmati. Potensi yang ketiga adalah budaya (cultural haritage). Indonesia merupakan negara yang mempunyai kekayaan budaya yang beragam. Setiap suku, kota, dan pulau mempunyai ciri khas, baik dari segi logat, baju, bangunan rumah, musik, maupun upacara-upacara adat, semuanya menjadi ciri khas bangsa Indonesia sebagai bangsa yang kaya budaya. Termasuk juga kekayaan hasil peninggalan sejarah terdahulu berupa benda cagar budaya. Ketiga unsur tersebut yang akan mendukung pesatnya kemajuan kepariwisataan Indonesia di masa yang akan datang.

Penggunaan media baru dalam promosi industry pariwisata tak dapat dielakkan. Perbedaan umum antara media lama dan baru terutama berkaitan dengan penulisan (dan pencapaian), penerbitan (produksi-distribusi) dan pengguna (audience). Hampir semua new media (media baru) memiliki karakteristik yang sama yaitu mengalami perubahan dalam produksi, distribusi dan penggunaan². Masalah yang ditemukan sehubungan dengan keuntungan dan perbedaan kapasitas media "tradisional" dan media "baru" sebagai saluran komunikasi.

Karakteristik media baru (new media) secara langsung maupun tidak akan menjadi pesaing, jika tidak dikatakan sebagai menggerus, posisi media tradisional. Media massa seperti koran, radio, televisi, dan sebagainya tidak lagi menjadi satu-satunya sumber informasi. Perbedaan media baru dari media lama; internet mencakup radio, film dan televisi,

2 . Lister, 2009. dan pendistribusian mereka melalui tekanan teknologi.

Internet sendiri memiliki keistimewaan karena terdapatnya karakteristik interaktivitas yang tidak dapat ditemukan pada media tradisional. Interaktivitas dalam konteks new media ini menunjukkan adanya kemampuan bagi para penggunanya (media) untuk terlibat secara langsung dan mengubah gambar atau teks yang mereka akses. Hal ini juga ditegaskan oleh Pavlik yang menyatakan bahwa interaktivitas dalam new media akan memberikan peluang kepada konsumen media untuk menjadi partisipan yang lebih aktif dalam dunia komunikasi yang diperantara3. Di sini pengguna new media ini bukan hanya menjadi viewer tetapi user .

Kita bisa mengidentifikasi empat kategori utama "media baru" yang berbagi saluran yang sama dan kira-kira berbeda dari tipe penggunaan, isi, dan konteks, sebagai berikut5: (1). Media Komunikasi interpersonal, (2). Media permainan interaktif, (3). Media pencarian informasi, (4). Media kolektif untuk berpartisipasi.

Media juga dapat dilihat dari 4 dimensi: (1)Kekuasaan dan ketidaksetaraan, (2)Integrasi sosial dan identitas, (3)Perubahan sosial dan pembangunan, dan (4)Ruang dan waktu.

Pada dimensi kekuasaan, media baru tidak lagi dapat sepenuhnya dikuasai oleh suatu bentuk kekuasaan. Kepemilikan maupun monopoli media tidak lagi dapat sepenuhnya mengontrol isi dan arus informasi. Media baru malah dapat berfungsi sebagai kontrol masyarakat terhadap penguasa. Saat ini terbuka akses yang setara sebagai pengirim, penerima dan partisipan dalam pertukaran dan jaringan informasi.

\footnotetext{
3 Pavlik, 1998: 137

${ }^{4}$ Lister, Dovey \& Giddings, 2003: 21

5 McQuail, 6", 2010
} 
Pada dimensi integrasi dan identitas, pertanyaannya adalah apakah media baru mendorong perpecahan atau penyatuan dalam masyarakat. Penggunaan internet misalkan, menimbulkan efek sosial yang berbedabeda namun membuka hubungan dan jaringan yang saling berintegrasi dan mungkin malah lebih mengikat.

Media baru menjembatani ruang privat dan publik. Media baru merekatkan kembali individu-individu setelah 'terpisahkan' akibat efek modernisasi. Pada dimensi perubahan sosial, media baru lebih berpotensi mendorong perubahan karena mereka lebih terlibat dan fleksibel dan kaya akan informasi. Media baru mengatasi rintangan jarak dan waktu. Teknologi baru membebaskan kita dari banyak batasan meskipun masih ada alasan sosial budaya mengapa aktivitas komunikasi masih terlokalisasi. Internet misalkan, meski tampak tanpa batasan tetapi masih terstruktur berdasarkan wilayah, terutama negara dan bahasa.

\section{B. Perspektif Penelitian}

Kajian ini akan memandang dari perspektif ekonomi, sosiologi, dan juga antropologi. Secara ekonomi, pariwisata memberi dampak dalam perluasan lapangan usaha dan kesempatan kerja, peningkatan income per kapita dan peningkatan devisa negara. Dalam sosiologi, kegiatan pariwisata terjadi interaksi sosial budaya antara pendatang dan penduduk setempat sehingga dapat menyebabkan perubahan dalam way of life masyarakat serta terjadinya integrasi sosial. Selanjutnya dalam antropologi, pengenalan akan budaya dan nilai-nilai kearifan lokal (local wisdom) yang terkandung dalam situs cagar budaya bisa lebih lestari dan dikenal secara meluas. Kondisi alam sangat mendukung karena wilayah Indonesia terdiri dari pulau-pulau dengan masyarakat yang pluralistis di dalamnya terkandung beraneka ragam suku, adatistiadat, dan kebudayaan (kepercayaan, seni, moral) yang berbeda-beda serta mempunyai potensi keindahan alam yang terdapat di seluruh penjuru tanah air. Hal ini yang menjadi daya tarik tersendiri bagi para wisatawan baik domestik maupun manca negara untuk berkunjung ke Indonesia .

Berkaitan dengan perspektif Timur dan Barat, Littlejohn (2005) mengatakan para ahli dari Timur cenderung fokus pada wholeness \& unity, sementara perspektif Barat (1) mengukur sebagian suatu bagian tanpa selalu mengintegrasikan sebagian tersebut kedalam proses yang menyatu/ menyeluruh, (2) teori-teori barat didominasi oleh visi individu. Kritiknya adalah bukti empiris yang menjadi andalan dunia Barat (nomothetic) perlu diinterpretasi (idiosinkratik), sehingga tidak ada kebenaran tunggal.

\section{Fokus Penelitian}

Berdasarkan pada uraian latar belakang di atas, maka rumusan masalah dalam penelitian ini mengambil fokus pada "Penggunaan New Media dalam Promosi Situs Cagar Budaya Pada Pariwisata Daerah di Indonesia".

Penggunaan media baru seperti twitter, facebook, dan situs internet dapat dimanfaatkan oleh pemerintah maupun pihak swasta untuk dapat mengenalkan objek-objek dan atraksi-atraksi wisata yang ada di daerah ini agar para pendatang tersebut dapat tinggal lebih lama. Hal ini menarik perhatian peneliti untuk mengkaji hal-hal berikut ini :

1. Penggunaan new media apa saja yang telah dan akan dilakukan sebagai sarana promosi cagar budaya pada pariwisata daerah? 
2. Bagaimana efektifitas penggunaan new media dalam kegiatan promosi tersebut?

\section{Definisi Istilah}

Definisi istilah yang digunakan dalam makalah ini adalah sebagai berikut:

- New Media: media komunikasi, yakni meliputi produk material sekaligus cultural dari sistem distribusi informasi massal yang ditujukan untuk khalayak luas dan dijalankan berdasarkan sistem pemasaran modern ${ }^{6}$.

- Promosi: kegiatan untuk mengarahkan seseorang atau organisasi kepada tindakan yang menciptakan pertukaran dan pemasaran. Promosi sangat penting dilaksanakan oleh perusahaan dalam memasarkan produk atau jasanya. Promosi pada hakekatnya adalah merupakan kegiatan yang ditunjukkan untuk mempengaruhi konsumen agar mereka dapat menjadi kenal akan produk yang ditawarkan oleh perusahaan pada mereka dan kemudian mereka menjadi senang lalu membeli produk tersebut. Promosi menurut Basu Swastha yaitu bahwa promosi dipandang sebagai arus informasi atau persuasi satu arah yang dibuat untuk mengarahkan seseorang atau organisasi kepada tindakan yang menciptakan pertukaran dalam pemasaran. Tujuan utama dari promosi adalah: menginformasikan, mempengaruhi, dan membujuk7.

- Páriwisata diartikan sebagai segala sesuatu yang berhubungan dengan wisata, termasuk pengusahaan objek dan daya tarik wisata serta usaha usaha yang terkait di bidang

Martin Lister et all, 2009.

7 Indriyo Gitosudarmo, dalam Basu Swastha, 1994: tersebut. Wisata diartikan sebagai kegiatan perjalanan atau sebagian dari kegiatan tersebut yang dilakukan secara sukarela dan bersifat sementara untuk menikmati objek dan daya tarik wisata (Direktorat Jenderal Pariwisata 1990) ${ }^{8}$.

- Pariwisata (tourism) adalah suatu perjalanan yang dilakukan untuk sementara waktu, yang diselenggarakan dari suatu tempat ke tempat lain, dengan maksud bukan untuk berusaha (business) atau mencari nafkah di tempat yang dikunjungi, tetapi semata - mata untuk menikmati perjalanan tersebut, guna pertamasyaan dan rekreasi atau memenuhi keinginan yang beranekaragam?.

- Pemasaran atau Promosi Pariwisata: membatasi pemasaran wisata sebagai upaya - upaya sistematis dan terpadu yang dilakukan oleh organisasi pariwisata nasional dan atau badan - badan usaha pariwisata pada taraf internasional, nasional dan lokal guna memenuhi kepuasan wisatawan baik secara kelompok maupun pribadi masing masing dengan maksud meningkatkan pertumbuhan pariwisata ${ }^{10}$.

- Mengenai situs cagar budaya" dalam didefinisikan bahwa:

\section{(1) Benda cagar budaya adalah:}

a. Benda buatan manusia, bergerak atau tidak bergerak yang berupa kesatuan atau kelompok, atau

\footnotetext{
${ }^{8}$ Undang - Undang Republik Incionesia Nomor 9 tahun 1990 tentang Kepariwisataan

${ }^{9}$ Yoeti: 1980

${ }^{10}$ Ibid.

${ }^{11}$ Pasal 1 ayat 1 Undang-undang Republik Indonesia No. 5 Tahun 1992 tentang Benda Cagar Budaya (diperbanyak oleh Suaka Peninggalan Sejarah dan Purbakala)
} 
bagian-bagiannya atau sisasisanya, yang berumur sekurangkurangnya 50 (lima puluh) tahun, atau mewakili masa gaya yang khas dan mewakili masa gaya sekurang-kurangnya 50 (lima puluh) tahun, serta dianggap mempunyai nilai penting bagi sejarah, ilmu pengetahuan, dan kebudayaan;

b. Benda alam yang dianggap mempunyai nilai penting bagi sejarah, ilmu pengetahuan dan kebudayaan.

Sedangkan, Situs adalah : lokasi yang mengandung atau diduga mengandung benda cagar budaya termasuk lingkungannya yang diperlukan bagi pengamanannya. Di mana "Perlindungan benda cagar budaya dan situs bertujuan melestarikan dan memanfaatkannya untuk memajukan kebudayaan nasional Indonesia"ז2.

\section{E. Landasan Teoritis}

Menurut Martin Lister (et al, 2006) terdapat dimensi historis dan institusional dalam kata 'media' dalam istilah 'new media' yang merujuk pada media komunikasi, yakni meliputi produk material sekaligus kultural dari sistem distribusi informasi massal yang ditujukan untuk khalayak luas dan dijalankan berdasarkan system pemasaran modern. Jelaslah bahwa media di sini merujuk pada pengertian perantara yang spesifik, yakni 'media massa' semacam Koran, radio dan televise dalam perbendaharaan bahasa Indonesia.

Kemudian dengan istilah media baru, Lister menunjuk beberapa karakter media baru yang ditandai yang ditandai

${ }^{12}$ Bab 1 pasal 2 Undang-undang Republik Indonesia No. 5 Tahun 1992 tentang Benda Cagar Budaya dengan penemuan dan pencanggihan teknologi gambar dan suara pada akhir tahun 80-an yang menyebabkan perubahan dimensi ideologis dan budaya dari penyebaran informasi, yaitu: (a) pergeseran situasi modernitas menuju posmodernitas, (b)pergeseran era industry (khususnya di Barat) menuju era pos-industri, dan (3)desentralisasi orde geo politik dunia.

Indikasi-indikasi perubahan tersebut dicirikan oleh kemunculan teknologi informasi dan komunikasi yang memunculkan persepsi-persepsi baru sehingga media baru sesungguhnya terbatas pada fenomena-fenomena glonal yang baru pula, antara lain: (1) pengalaman tekstual baru oleh sebab munculnya genre dan bentuk tekstual yang dikonsumsi masyarakat banyak, melalui game, hiperteks dan sinema dengan efek khusus (2 cara representasi baru dengan munculnya kemungkinan dan pengalaman representasi melalui lingkungan virtual dan layar computer interaktif. (3) relasi baru antar subjek (pengguna/ konsumen) dengan teknologi media yang merubah penggunaan dan resepsi masyarakat terhadap citra dan media komunikasi sehari-hari. (4) relasi baru menyangkut persoalan ketubuhan (embodiment), komunitas dan identitas oleh karena pengalamn personal dan sosial baru dalam memahami konsep wajtu, ruang dan tempat. (5) konsepsikonsepsi baru tentang hubungan fisik manusia dengan teknologi media karena tantangan untuk memahami perbedaan antara yang manusiawi dan artificial, yang alamiah dan teknologis, yang nyata dan yang maya. (6) pola organisasi dan produksi baru yang menggeser keadaan budaya, industry, ekonomi, kepemilikan, kontrol dan regulasi.

Karakteristik media baru memberikan pengaruh pada proses komunikasi antar manusia, terutama 
berkaitan, dengan cara dan budaya masyarakat dalam menggunakan dan memahami teknologi komunikasi. Apakah karakteristik media baru menyebabkan berubahnya kebiasaan komunikasi ? Sebagaimana diingatkan Mcluhan bahwa setiap ekstensi teknologi akan menyebabkan modifikasi atau hilangnya beberapa ekstensi.

Karakteristik interactivity dari media baru menjadikan seperti komunikasi interpersonal. Namun demikian, karakteristik ini membawa persoalan menyangkut 'social presence'. Standar penilaian kesuksesan komunikasi interpersonal salah satunya adalah kehadiran secara fisik dari para partisipan komunikasi. Biocca et al (2003) memodifikasi 'social presence' sebagai keterlibatan orang-orang yang berinteraksi melalui kesadaran bersama dengan menggunakan media baru. Interaksi on line dapat membentuk virtual community tanpa kehadiran secara fisik. Akan tetapi yang menjadi pertanyaan apakah dalam interaksi on line dapat menumbuhkan 'sense of community? Bagaimana menumbuhkan kesadaran bersama dalam media baru? Bagaimana computer mediated communication ( $\mathrm{cmc}$ ) sebagai media yang kurang tanda-tanda non verbalnya, dimana tanda-tanda non verbal tersebut sering dianggap sebagai aspek terpenting dalam komunikasi interpersonal? Bagaimana dengan identitas dan kredibilitas para partisipan yang berinteraksi?

Karakteristik interaksi yang dimiliki internet memungkinkan proses komunikasi yang terjadi tidak bersifat satu arah selayaknya yang terjadi di media trađisional, melainkan menjadi Iebih interaktif melalui media baru (new media). Selanjutnya, era teknologi digital dan teknologi komunikasi telah mengubah arah komunikasi yang selama ini menganut pola broadcast. Jika model broadcast adalah komunikai satu arah, maka dengan kehadiran teknologi komunikasi itu bisa menjadi dua arah bahkan lebih atraktif. Komunikasi terjadi tidak lagi memakai pola dari sumber yang satu menyebar ke banyak (broadcast), berpusat, khalayak bersifat pasif, dan penerima berada dalam posisi terisolasi ${ }^{23}$, melainkan lebih dinamis, tidak tersentral, sampai pada melibatkan khalayak.

Proses adaptasi penggunaan media sebagai sarana promosi, jika dikaji dalam dimensi antropologi merujuk pada pendapat Bertalanffy [et.al,] ${ }^{24}$ yang mengemukakan seperangkat asumsi "open-system" tentang sifat manusia sebagai entitas hidup yang adaptif, yaitu:

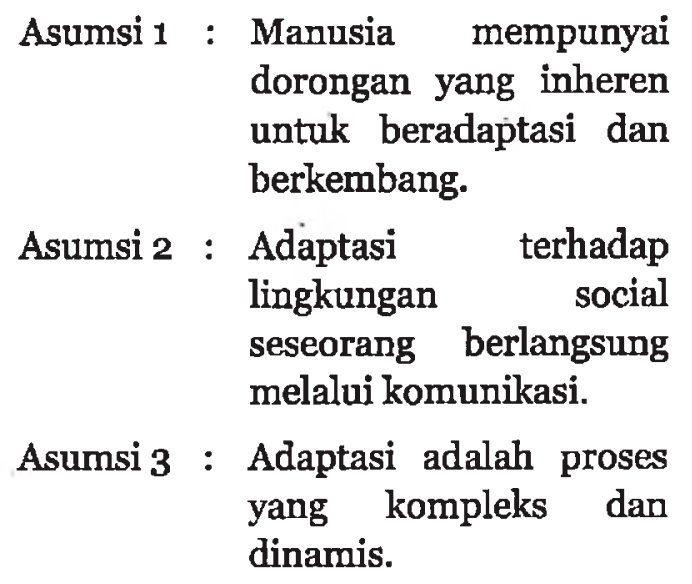
Asumsi 2 : Adaptasi terhadap lingkungan social seseorang berlangsung melalui komunikasi.

Adaptasi memang merupakan proses yang sangat kompleks, karena banyak hal yang turut mempengaruhi proses adaptasi antarbudaya, sebagai dapat kita lihat pada model adaptasi yang dikemukakan oleh Ting-Toomey sebagai berikut:

${ }_{13}^{13}$ Levy, 2001:223
${ }^{14}$ Bertalanffy [et.al,] dalam Wiseman (1995: 172) 


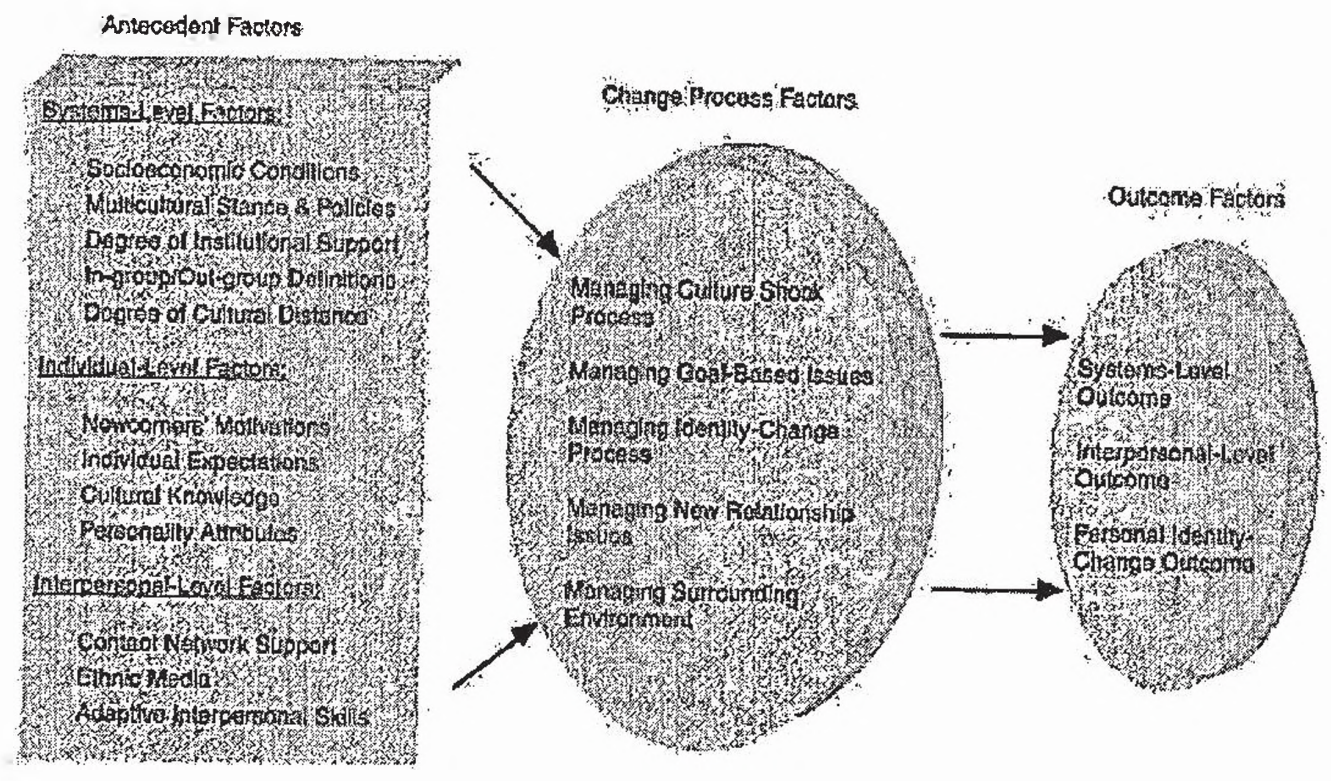

Gambar 1: An Intercultural Adaptation Model: Antecedent, Process and Outcome Factors.

(Sumber: Ting-Toomey, Stella. 1998. Communicating Across Cultures. New York: The Guilford Press, p. 236)

Memperkuat tiga asumsi tersebut, ada tiga factor terjadinya proses adaptasi budaya, yaitu faktor antiseden, faktor prọses dan faktor hasil

1. Faktor antiseden:

a) Faktor tingkat system (Systemlevel factors)

a. Faktor level system adalah unsur-unsur yang ada pada lingkungan setempat yang mempengaruhi adaptasi pendatang kepada budaya baru, meliputi kondisi social ekonomi, sikap budaya setempat dan kebijakan institusi, institusi local (seperti sekolah, tempat kerja, layanan social dan media massa), pendefinisian ingroup dan outgroup, jarak budaya (meliputi perbedaan dalam hal nilai budaya, konsep diri, bahasa dan gaya komunikasi, agama, system ekonomi dan politik). b) Faktor level individu (individual-level factors)

a. Beberapa factor level individu yang juga mempengaruhi adaptasi antarbudaya, diantaranya motivasi, harapan individu, budaya, interaksi yang berbasis pengetahuan, dan atribut-atribut personal.

c) Faktor level interpersonal (interpersonal-level factors)

a. Faktor level interpersonal yang dapat mempengaruhi adaptasi antarbudaya meliputi hubungan jaringan antar muka (seperti jarngan social), kontak bermedia (seperti menggunakan media massa), dan factor kerampilan. interpersonal.

2. Faktor proses perubahan

Proses adaptasi antarbudaya perubahan dan tantangan identitas bagi pendatang baru, seperti perbedaan dalam hal kepercayaan, nilai dan norma situasional antara budaya 
setempat dan pendatang. Gegar budaya termasuk salah satu unsure yang mempengaruhi proses adaptasi antarbudaya.

\section{Faktor hasil (outcome)}

Faktor hasil meliputi ketiga dimensi dari factor antiseden, yaitu hasil pada level system, hasil pada level antarpersonal dan hasil perubahan identitas personal.

Dalam perspektif ekonomi, Menurut Philip Kotler, pemasaran adalah kegiatan manusia yang diarahkan pada usaha untuk memuaskan keinginan dan kebutuhan melalui proses pertukaran ${ }^{15}$. Menurut William J. Stanton, pemasaran adalah sistem keseluruhan dari kegiatan usaha yang ditujukan untuk merencanakan, menentukan harga, mempromosikan dan mendistribusikan barang dan jasa yang dapat memuaskan kebutuhan kepada pembeli yang ada maupun pembeli potensial ${ }^{16}$.

\section{F. Promosi Situs Cagar Budaya di Cirebon}

Situs Cagar Budaya merupakan transmisi pesan dari generasi sebelumnya ke generasi saat ini. Selama ini, situs cagar budaya sering digunakan sebagai media dalam penyampaian informasi atas simbol-simbol kesejarahan, namun eksplorasi pesan dari situs tersebut masih kurang. Dalam promosi pariwisata, makna yang dibawa dari simbol situs cagar budaya bisa dikaji lebih dalam lagi untuk memberi informasi yang lebih rinci dari aspek sosiologis, antropologis, dan biologis. Salah satu daerah yang kaya akan situs cagar budaya adalah kota Cirebon. Peneliti menentukan Cirebon sebagai objek penelitian dengan pertimbangan banyaknya situs cagar budaya yang

\footnotetext{
${ }^{15}$ Swastha, 1990: 4

${ }^{15}$ Swastha, 1990: 5
}

terdapat di tempat tersebut yang memiliki makna bagi peradaban kehidupan saat ini.

Promosi yang dilakukan melalui pembuatan situs dilakukan oleh pihak keraton kasepuhan dengan http://kasepuhan.com dan juga dilakukan oleh pemerintah daerah melalui http://www.disporbudpar.cirebonkota.go. id. Selain itu, ada pihak swasta yang bergerak dalam industri pariwisata membuat akun twitter khusus untuk memperkenalkan segala informasi tentang Cirebon melalui @boutcirebon.

Kota Cirebon adalah salah satu daerah tujuan wisata di Provinsi Jawa Barat. Kota Cirebon adalah sebuah kota mandiri terbesar kedua di Provinsi Jawa Barat, setelah ibu kota Jawa Barat, yakni Kota Bandung. Kota ini beradadi pesisir Laut Jawa, di jalur pantura. Jalur Pantura Jakarta- Cirebon -Semarang merupakan jalur terpadat di Indonesia. Kota Cirebon juga adalah kota terbesar keempat di wilayah Pantura setelah Jakarta, Surabaya, dan Semarang. Karena letaknya yang sangat strategis yakni di persimpangan antara Jakarta, Bandung, dan Semarang, menjadikan kota Cirebon sangat cocok dan potensial untuk berinvestasi dalam segala bidang investasi seperti hotel, rumah makan, pusat perbelanjaan baru, pendidikan.

Dengan didukung oleh kegiatan ekonomi yang baik dan terpadu menjadikan Kota Cirebon berkembang menjadi Kota Metropolitan ketiga di Jawa Barat setelah Metropolitan BoDeBeK (Bogor ,Depok ,Bekasi) yang merupakan hinterland / kota penyangga bagi ibukota Jakarta dan Metropolitan Bandung. Kota Cirebon merupakan pusat bisnis, Industri, dan jasa di wilayah Jawa Barat bagian timur dan utara. Banyak sekali Industri baik skala kecil, menengah, dan besar menanamkan modalnya di kota wali, Cirebon. Dengan didukung oleh banyaknya orang - orang yang bekerja, beraktifitas dan menuntut ilmu di Kota 
Cirebon, sekitar kurang lebih 1 juta orang, menjadikan kota Cirebon lebih hidup. Pembangunan di Kota Cirebon juga menggeliat dan menunjukkan respons positif, hal ini terbukti dengan banyaknya bangunan - bangunan besar dan tinggi yang berada di jalan - jalan utama kota Cirebon ${ }^{17}$.

Melihat kondisi demikian, maka Pemerintah Kota Cirebon dewasa ini sedang memacu pembangunan sektor pariwisata, hal ini terlihat dengan usah dibuatnya merek dagang atau branding kepariwisataan Cirebon yakni "Cirebon the Gate of Secret " (Cirebon Pintu Gerbang Rahasia) ${ }^{18}$. Dari sini kemundian muncul pertanyaan dari kita hal-hal apa sajakah yang telah dilakukan oleh Dinas Kepariwisataan Kota Cirebon dalam rangka memasarkan dan memperkenalkan atraksi-atraksi wisata yang ada di Kota Cirebon ini. Untuk itulah penulis bermaksud untuk meneliti tentang kegiatan promosi melalui media baru (new media) yang dilakukan oleh Dinas Kepariwisataan Kota Cirebon tersebut.

Sebagai kota yang duTunya berbentuk kerajaan, keunikan Cirebon adalah memiliki situs cagar budaya yang dimiliki Cirebon berjumlah lebih dari 400 situs $^{19}$. Cirebon tidak hanya memiliki tiga buah keraton, yaitu Keraton Kasepuhan, Keraton Kanoman dan Keraton Kacirebonan. Keberađaan Keraton Kasepuhan dan Keraton Kanoman adalah bukti keberadaan politik 'devide et impera' kaum kolonialis. Perpecahan yang dibuat oleh Belanda untuk melemahkan perlawanan masyarakat berakibat timbulnya dua keraton ini. Sesuai dengan namanya maka Keraton Kanoman adalah keraton yang lebih muda, yang muncul belakangan. Selain kedua keraton itu

\footnotetext{
17.
}

(http://www.disporbudpar.cirebonkota.go.id), diakses 20 Desember 2013

is Ibid.

39 tbid. seharusnya masih ada Keraton Kacirebonan. Ketiganya memiliki ciri menghadap ke Utara, di sebelah kiri Kraton ada mesjid, dan di taman keraton ada patung macan perlambang Prabu Siliwangi, tokoh sentral dalam sejarah Cirebon.

Cirebon sendiri merupakan tempat yang menarik untuk mempelajari akulturasi budaya yang terjadi di kota pelabuhan yang cukup aktif ini. Motif megamendung yang merupakan motif khas batik Cirebon merupakan pengaruh Oriental seperti yang biasa tampak pada gambar awan di keramik-keramik asal Tiongkok. Warna-warna yang lebih cerah tidak hanya mewarnai batik mereka, tetapi juga mewarnai interior bangunannya, warna ini berbeda dari warna batik Jogja maupun Solo yang awalnya hanya memakai satu warna.

Keraton ini memiliki pagar dan gapura yang terbuat dari susunan bata merah, dan konon direkatkan tanpa menggunakan semen sama sekali. Dalam keraton ini terdapat nuansa asimilasi antara budaya Jawa, Sunda bahkan Cina dan Eropa. Di halaman keraton terdapat patung 2 ekor macan putih. Dalam areal keraton juga terdapat Masjid Agung Sang Cipta Rasa.

Keraton di Cirebon memiliki beberapa kesamaan yang mungkin menjadi standar dengan keraton-keraton di Cirebon, antara lain menghadap ke Utara, lalu di sebelah Timur terdapat masjid, memiliki alun-alun untuk rakyat berkumpul, serta memiliki patung macan perlambang Prabu Siliwangi. Namun dari ketiga keraton yang ada di Cirebon (Kasepuhan, Kanoman dan Kacirebonan), keraton Kasepuhan nampaknya terlihat yang paling terawat.

Di dalam museum yang berada di Utara keraton terdapat benda-benda peninggalan kerajaan seperti peralatan perang, meriam dan kereta kencana yang digunakan saat berperang. Kereta ini 
disebut Kereta Singa Barong, berkepala gajah yang belalainya memegang trisula (pengaruh Hindu), bersayap garuda (pengaruh Islam) dan berekor naga (pengaruh Cina). Kereta ini sudah memiliki teknologi shockbreaker dan juga memiliki mekanik untuk mengepakkan sayapnya. Namun kereta ini sejak 1942 sudah tidak difungsikan lagi dan hanya keluar untuk 'dimandikan' setiap tanggal 1 Syawal. Sayang kondisi tempat ini kurang terlalu terawat, padahal barang di dalamnya sudah berusia ratusan tahun. Sedangkan di museum di bagian Selatan Keraton terdapat perhiasan, pernakpernik, piring, dan perlengkapan keraton yang digunakan saat jaman Sunan Gunung Jati.

Keraton Kasepuhan adalah keraton yang paling terawat di antara keratonkeraton di Cirebon. Keraton awal adalah keraton Pakungwati yang berdiri di belakang keraton Kasepuhan, dibangun oleh Prabu Cakrabuana (tahun 1445). Keraton tersebut kemudian diperluas pada tahun 1529. Mesjid Agung yang berdiri di Timur keraton dibangun pada tahun 154920. Ketika masuk ke ruang utama Keraton, dengan permohonan maaf, pemandu wisata meminta pengunjung untuk melepas alas kaki, seperti umumnya masuk ke rumah masyarakat Jawa.

Peneliti tertarik mengeksplorasi situs cagar budaya di keraton Kasepuhan yang berada di tengah kota Cirebon. Sangat mudah untuk mencapai keraton ini, tepatnya berada di Jl Keraton Kasepuhan No. 43. Letaknya begitu dekat dengan pusat kota, warga Cirebon sendiri banyak yang belum pernah masuk ke keraton ini. Namun, tempat ini tak pernah sepi dari wisatawan nasional maupun internasional yang senantiasa berkunjung untuk berlibur ataupun mengadakan penelitian. Wisatawan dari luar negeri itu

${ }^{20}$ http://kasepuhan.com banyak yang berasal dari Jepang, Australia, Inggris, dan Belanda ${ }^{21}$. Umumnya mereka datang karena tertarik mengenal budaya sejarah Cirebon, yang mereka dapatkan dari keluarga atau kerabatnya yang pernah berkunjung ke Indonesia. Beberapa wisatawan tersebut, yang berasal dari Jepang dan Belanda bahkan berkunjung berkali-kali ke Cireboun karena merasa memiliki kedekatan sejarah dengan daerah ini22.Ini menjadi tantangan bagi pengelola pariwisata Cirebon untuk terus mengadakan promosi agar lebih banyak lagi warga sekitar Cirebon dan wisatawan domestik yang tertarik untuk berkunjung. Begitupula tantangan agar wisatawan luar negeri.

\section{G. Kritik}

Usaha situs cagar budaya yang terus mengembangkan nilai keaslian dan keotentikan budaya, harus berpadu dengan masuknya teknologi komunikasi melalui media internet atau situs jejaring sosial. Media promosi tradisional tidak serta merta ditinggalkan, namun berjalan beriringan dengan penggunaan media baru. Perbandingan efektifitas penggunaan media tradisional dan penggunaan media baru sebagai sarana promosi pariwisata adalah kekurangan yang belum dilakukan oleh peneliti.

Selanjutnya, penggunaan media baru yang dilakukan sebagai sarana promosi pariwisata, seringkali tidak berjalan beriringan dengan perawatan situs cagar budaya di Indonesia. Tuntutan modernitas dan keinginan pasar seringkali menjadikan industri pariwisata berkutat pada promosi yang sifatnya profit oriented dan pragmatis, tapi kurang mengedepankan nilai-nilai kearifan lokal yang terkandung dalam situs cagar budaya yang bisa menjadi 'nilai jual' agar

\footnotetext{
${ }^{21}$ Rì'aeni, 2012.

${ }^{22}$ Wawancara dengan pernandu wisata
} Keraton Kasepuhan, Mulyana, 10 Februari 2012. 
wisatawan bisa kembali mendatangi tujuan wisata tersebut. Seringkali, kajian tentang makna nilai-nilai kearifan lokal yang terkandung dalam situs cagar budaya dianggap tidak menarik karena tidak memiliki unsur kebaruan. Apa yang menjadi makna dari sejarah peninggalan sejarah masa lalu misalnya saja makna simbol dari suatu bangunan situs, menjadi kurang diminati untuk dikaji dan diulas lebih dalam lagi, dalam kajian ilmu komunikasi atau komunikasi pariwisata. ()

\section{Daftar Pustaka}

Brannan, Tom. (1998). Komunikasi

Pemasaran Terpadu: PT.

Gramedia Pustaka.

Berger \& Chaffee (Eds), 1987. Handbook

of Communication Science.Beverly Hills,Calivornia:Sage

Creeber, G. (2009). Digital Theory: Theorizing New Media. Dalam Creeber, G. dan Martin, R. Digital Cultures, Understanding New Media. McGraw-Hill, hal.11 - 22.

Gudykunst, William

B.(Ed), 1983. "Intercultural

Communication Theory "Beverly Hills, California:Sage Publications

Lister, Martin et al. (2009) New Media: A Critical Introduction. $2^{\text {nd }}$ Ed. Routledge.

Littlejohn, Stephen W. Communication and Media (2001). Theories of Human Communication. 7 th Edition.

Belmont,California:Wadsworth Publishing Companv.

Levy, P. (2001). Cyberculture. Minnesota: University of Minnesota Press

Liliweri, Alo. (2001). Gatra-gatra Komunikasi Antarbudaya,Pustaka Pelajar,Yogyakarta,

McQuail, Dennis. (2010) McQuail's Mass Communication Theory, $6^{\text {th }}$, NewYork, Sage Publishing.

McLuhan, Marshall.( 1964) "The Medium is the Message" From Understanding Media: The Extensions of Man (New York: Signet)
Pavlik, John V. (1998), New Media Technology: Cultural \& Commercial Perspectives, 2nd ed., New York, Allyn \& Bacon.

Rogers, Everett M. (1986). Communication Technology, The New Media in Society, New York: The Free Press A Division of Mac Millan, Inc.

Ri'aeni, Ida. (2012) Makna Pengabdian dan Peran Diri Pemandu Wisata. Jurnal Communique, Universitas Pelita Harapan, Vol 9, Juli 2012. ISSN:1829-5851.

Swastha, Basu. (1999). Manajemen Pemasaran Modern. Yogyakarta: Liberty.

Terene A. Shimp. (2003). Periklanan Promosi Aspek Tambahan Komunikasi Pemasaran Terpadu. Jakarta: Erlangga.

Ting-Toomey, Stella. 1998. Communicating Across Cultures. New York: The Guilford Press

Yoeti A. Oka. (1998). Pemasaran Pariwisata Terpadu. Bandung: Angkasa

Yoeti A. Oka. (1992). Anatomi Pariwisata. Bandung : Angkasa.

Yoeti A. Oka. (1995). Ekonomi Pariwisata Introduksi Informasi dan Implementasi. Jakarta: PT. Gramedia Pustaka Utama

http://www.budpar.go.id diakses 20 Desember 2014

http://www.disporbudpar.cirebonkota.go. id diakses 20 Desember 2014

http://kasepuhan.com diakses 29

Desember 2014 